\title{
The Relationship Between Frailty and Depression, Quality of Life, Disability, and Hospitalization Among Community-Dwelling Older Adults
}

Audai A. Hayajneh ( $\square$ aahayajneh@just.edu.jo )

Jordan University of Science and Technology https://orcid.org/0000-0002-8141-3530

Hanan Hammouri

Jordan University of Science and Technology

Eman S. Al-Satari

King Saud University

Debra C. Wallace

University of North Carolina at Greensboro

Mohammad Rababa

Jordan University of Science and Technology

Research article

Keywords: Frailty, Depression, Quality of Life, Disability, Hospitalization, Community-Dwelling Older Adults

Posted Date: November 20th, 2020

DOl: https://doi.org/10.21203/rs.3.rs-107334/v1

License: (c) (1) This work is licensed under a Creative Commons Attribution 4.0 International License.

Read Full License 


\section{Abstract}

Background: Frailty syndrome is characterized by a decline in physiological and psychological reserve that leads to poor health outcomes.

Objectives: The current study explored frailty and its impacts on health outcomes among older adults in close-knit Jordanian communities.

Methods: A secondary analysis ( $N=109)$ of community-dwelling older adults aged 60 years or over was conducted. The Arabic version of the culturally adapted Tilburg Frailty Indicator, the Geriatric Depression Scale, the Montreal Cognitive Assessment, the SF-36 Quality of Life survey, and disability self-reports were used.

Results: Despite Jordanian communities being very close-knit, the results indicated a high prevalence of frailty (78\%) and depression (38\%) and poor outcomes of cognitive dysfunction and low quality of life among the participating older adults. Further, the prevalence of frailty was found to be 4.2 times higher among females than males and 7.2 times higher among single older adults than married older adults.

Conclusion: A high prevalence of frailty and its related adverse outcomes was found among older adults in Jordan.

\section{Introduction}

Frailty and an aging population have major implications on the delivery of health care and social services. The combination of physical weakness syndrome, dependence on others, depression, low quality of life, and disability among older adults often increases the need for medical visits, treatment, and hospitalization [1]. Frail elderly persons face difficulties carrying out daily tasks, which increases the risk of injury, falls, fractures, hospitalization, and premature death [2]. A three-year follow-up study conducted by Bandeen-Roche and colleagues [3] found that frail older adults had a 3-fold higher risk of death compared to non-frail older adults. Impaired physical function was defined by Fried and colleagues [4] as the acquisition of older adults to three or more of the following five components: shrinkage (weight loss), weakness, exhaustion, low gait speed, and low physical activity.

There is evidence of an association between cognitive decline and physical weakness resulting from structural and physiological alterations in the brain [5]. A recent study demonstrated that 16 to $35 \%$ of older adults experienced common symptoms of depression, with a prevalence of depression of up to 46.5\% among frail people [6]. Cognitive frailty can be classified as both reversible and nonreversible [7]. Depression symptoms in frail older adults are associated with poor outcomes, which include reduced quality of life, increased demand for healthcare services, and increased comorbidity and mortality rates $[7,8,9,10,11]$. 
The diagnosis of depression in older adults is often complicated due to the presence of comorbid conditions, pain, disability, and fragility $[12,13,14]$. Many studies have confirmed the association between frailty and disability among older adults and have indicated that frail and depressed older adults are more likely than non-frail older adults to develop disabilities or experience a worsening of their disabilities [8]. These trends in frailty and depression among older adults are similar across countries around the world, including Spain, Italy, Korea, the Netherlands, and the USA. For example, in Italy, frailty explained variance in both depression and somatic disease, though depression had its own contribution to disease [12]. Therefore, it remains unknown whether end-of-life depression and frailty are factors for adverse conditions, or if they share mutual underlying mechanisms that affect one another [15].

In the literature, no studies have explored the associations of frailty with depression, physical and social functions of quality of life (QOL), disability, and hospitalization among older adults in Middle Eastern countries such as Jordan. Further, research on the interventions required for improving the QOL of frail older adults in Jordan remains scarce. Therefore, the current study aimed to describe and explain frailty and depression, the QOL perspectives of physical and social functions, and hospital use among community-dwelling older outpatients in the context Jordanian culture. The study was guided by the following research questions: 1) What is the level of frailty among community-dwelling older adults Jordan? 2) What are the levels of depression, physical and social functions of QOL, and disability among community-dwelling older adults Jordan? 3) What relationships exist between life course determinants and frailty in the context of Jordan? 4) What are the association of frailty with depression, physical and social functioning QOL, disability, and hospitalization in the context of Jordan?

\section{Methods}

\section{Design and Participants}

This study was a secondary data analysis of existing cross-sectional data obtained from 109 community-dwelling older adults in Jordan [16]. Convenience sampling was used in the original study. A total of 109 Jordanian community-dwelling older adults from Irbid, (aged 60 years or over) participated in the original study. The participants were recruited through local community organizations and clinics.

\section{Data collection}

The participants were interviewed face-to-face by native Arabic speakers. The interviews lasted 15 to 30 minutes each and were held in private locations, which included private rooms in community centers, clinics, and other community sites. A G*Power calculation indicated that a minimum sample size of 109 participants would be required to meet a small effect size of 0.15 , power of 0.80 , and level of significance of 0.05 .

\section{Instruments}


Several measures were used to collect data for this secondary analysis. A tool was developed by the research to collect data on the life course determinants (age, gender, education, income, and marital status), social support (living with others), and health history (comorbidities) of the participants. The participants were screened for frailty using the Tilburg Frailty Indicator (TFI). The original TFI, developed by Gobbens and colleagues [17], comprises 15 items that target physical, psychological, and social domains. The TFI has been translated and validated to be culturally suitable for the Jordanian population [16]. The Arabic version of the Geriatric Depression Scale (GDS-15), a questionnaire comprising 15 yes-no questions, was used to measure the depression levels of the participants. The total possible score of the questionnaire ranges from 0 to 15, with scores categorized as follows: $(0-4)=$ normal, $(5-8)=$ mild depression, $(9-11)=$ moderate depression, and (12-15) = severe depression [18]. The Arabic version of the GDS-15 was validated by Chaaya and colleagues [19].

The Montreal Cognitive Assessment (MoCA), used to screen for Mild Cognitive Impairment (MCI) and Alzheimer's disease, was developed by Nasreddine and colleagues [20] (2005). This test is a 30-point test and has a completion time of 10 minutes. A score of 26 or above (20/25 or above in the case of the presence of psychometric issues) denotes no cognitive impairment, whilst a score below 26 (20/25 or below in the case of the presence of psychometric issues) indicates impaired cognition [20]. The test includes ten items aimed at evaluating different cognitive domains. This tool has been validated among Arabic-speaking elderly participants in Cairo, Egypt [21].

The Physical Functioning test (PF) (10 items) and the Social Functioning test (SF) (two items) are subscales derived from the validated Arabic version of the SF-36 tool used to measure quality of life domains [22,23]. Each test was standardized to a 0-100 scoring scale, with lower scores denoting lower functioning and higher scores denoting higher functioning and higher health-related quality of life (HRQOL) in the different domains. Finally, self-reports were used to measure disability and any incidences of hospitalization during the past year.

\section{Data Analysis}

Descriptive statistics were used to describe the sample and major variables and included frequencies, percentages, and measures of central tendency, as shown in Table 1 and Table 2. Missing data were assessed and normality tests (Q-Q plots) were conducted for each interval level outcome variable. To answer the four research questions, several statistical tests were conducted. The binomial test, linear regression, logistic regression, the chi-squared test of independence, and the Levene test for unequal variances were conducted, as well as the Tukey HSD and odds ratios. Significance was tested at alpha level $=0.05$. The JMP software was used for data analysis [24] .

\section{Ethical Considerations}

In the original study, human subject protection included obtaining approval from the Ethical Committee at a Jordanian university (Ref\# 34/77/2014). The original study [16] included an informed consent form which described the purpose of the study, data collection procedures, and potential benefits. The form 
also assured the participants that their participation was voluntary, that they had the right to withdraw from the study at any time without consequences, and that their information would be kept confidential. The informed consent forms were written in Arabic in order to make them comprehensible for the participants. In the current study, deidentified data were used for the secondary analysis report.

\section{Results}

The average age of the community-dwelling older adults enrolled in this study was 67 years $(S D=6.95)$. The majority of the participants $(61 \%)$ were male, and $68 \%$ of the participants were married. The education levels of the participants were varied, with $32 \%$ of the participants being illiterate, $34 \%$ being high school graduates, and $34 \%$ being university graduates. As for monthly income levels, $48 \%$ of the participants had a monthly income of less than $450 \mathrm{JOD}$. The majority of the participants (83\%) were living with others, and each participant had an average of $2.6(\mathrm{SD}=1.94)$ health conditions. One-third of the participants (30\%) reported having been hospitalized during the past year (see Table 1 and Table 2).

Around $78 \%$ of the participants were found to be frail. Using the binomial test (P-value $<0.001)$, the number of frail people was found to be significantly higher than the number of non-frail people (22\%). Around $38 \%$ of the participants were found to suffer from depression, and $6 \%$ had a disability. The QOL dimensions reflected moderate scores of $55 \%$ and $58 \%$ in both PF and SF of QOL, respectively. These frailty and depression levels indicated a highly vulnerable sample of older adults. Linear regression was used to assess the relationship between age and frailty, and the model was significant (with $\mathrm{F}_{(1,103)}$ = 8.9162 and $p$-value $<0.004)$. This indicates that age is significant in predicting the prevalence of frailty, using the equation: Prevalence of Frailty $=-2.409469+0.1386884^{\star}$ Age. Therefore, increased age was associated with a higher prevalence of frailty. A Pearson Chi-square test of independence was utilized to compare between male and female participants, with a significant interaction found $\left(X^{2}(1)=6.68, p<\right.$ $0.001)$.

Using the odds ratio, females were found to be 4.2 times more likely to be frail $(90.7 \%)$ than males (69.7\%). Further, a Pearson Chi-square test of independence was utilized to compare between single and married participants, with a significant interaction found $\left(X^{2}(1)=8.217, p<0.005\right)$. Single older adults were found to be 7.2 times more likely of being frail (94.1\%) than married older adults (69\%). As shown in Table 3, analysis of variance (ANOVA) was used to compare between the participants based on their levels of education (i.e. illiterate, high-school graduate, or university graduate). The unequal variances were insignificant, with a Levene P-value $=0.58$. Significant differences existed between the participant groups based on their levels of education $(F(2,94)=7.004$, P-value $=0.0015)$. The Tukey-Kramer HSD indicated a higher prevalence of frailty among illiterate participants in comparison to high-school graduates and university graduates.

The prevalence of frailty was higher among participants who were living alone than participants who were living with others. A result of $t_{107}=2.1$ with P-value $=0.019$ indicated that the average frailty score of participants who were living alone $(8.5 \pm 3.4)$ was significantly higher than the average score of 
participants who were living with others $(6.7 \pm 3.3)$. The final research question examined the associations of frailty with depression and poor outcomes, low quality of life (physical function and social function), disability, and hospitalization during the past year among community-dwelling older adults in Jordan. A Pearson Chi-square test of independence was used to compare between frail and nonfrail participants based on depression levels (GDS-15 score), indicating a significant interaction $\left(X^{2}(1)=\right.$ $11.25, p<0.001)$. Using the odds ratio, it was found that frail older adults were 9.3 times more likely $(45.9 \%)$ than non-frail older adults $(8.3 \%)$ to be depressed. Further, a Pearson Chi-square test of independence was used to test the association between frailty and cognitive impairment. A significant interaction was found $\left(X^{2}(1)=8.78, p=0.003\right)$, whereby frail older adults were 5.1 times more likely than non-frail older adults $(16.7 \%)$ to have impaired cognition $(50.6 \%)$.

A result of $t_{107}=-3.8$ with P-value $<0.001$ indicated that the PF average of frail participants $(50.1 \pm 26.9)$ was significantly lower than the PF average of non-frail participants $(72.7 \pm 20.2)$. Similarly, a result of $t_{105}=-4.11$ with P-value $<0.001$ indicated that the SF average of frail participatns $(53.7 \pm 21.9)$ was significantly lower than the SF average of non-frail participants $(74.5 \pm 19.4)$. We fitted a logistic regression to examine the impact of frailty on disability. The model was significant $\left(X^{2}{ }_{(1)}\right)=6.09$ and Pvalue $=0.014)$, and the estimate for the prevalence of frailty was also significant $(P$-value $=0.027)$.

The estimated probability was:

$$
P(x)=\frac{1}{1+e^{5.8-0.35 x}}
$$

Additionally, the odds ratio of 1.42 indicated that the chance of disability increased by $42 \%$ for each oneunit change in the prevalence of frailty. We fitted a logistic regression to examine the impact of frailty on hospitalization during the past year. The model was not significant $\left(\mathrm{X}^{2}{ }_{(1)}\right)=3.24$ and P-value $=0.071$ ); thus, no association was found between frailty and hospitalization during the past year.

\section{Discussion}

A high prevalence of frailty was found among older adults in Jordan. The prevalence of frailty among community-dwelling older adults in Jordan was found to be $78 \%$, which is consistent with studies conducted in other countries. Biritwum and colleagues [25] compared between China, Ghana, India, Mexico, Russia, and South Africa based on the prevalence of frailty and disability. China had the lowest prevalence of frailty among older adults (13.1\%), whilst India had the highest prevalence (55.5\%). Despite Jordanian communities being very close-knit and older adults in Jordan therefore receiving ample social support from their relatives and community members, the prevalence of frailty among older adults in Jordan is high. Therefore, healthcare providers working among close-knit communities in Jordan should focus on combating frailty among older adults in their later stages of life [16]. 
Several life course determinants were found to be associated with frailty. Increased age was found to be associated with increased frailty scores. Further, the prevalence of frailty was higher among female participants than male participants, which may be explained by the fact that women live longer than men and suffer from more adverse health conditions [26]. Our study findings are consistent with the study of Zhang, Guo, Gu and Zhao [26], which found a frailty prevalence of $5.4 \%$ in males compared to $8.8 \%$ in females. The literature has reported contradictory findings regarding the association between frailty and being female. For example, a previous systematic review reported that in comparison to males, the lower risk of mortality among females puts them at a lower risk of becoming frail, whilst the lower quality of life among females increases their risk of frailty [27]. In the present study, the prevalence of frailty was higher among single older adults than married older adults, which is in concordance with the findings of a recent study by Trevisan and colleagues [28]. Similarly, living alone was found to be a risk factor for frailty, which has also been reported in a previous study [29]. This is also consistent with the findings of de Labra and colleagues [30], which indicated that frailty was associated with social determinants and reduced quality of life.

As with regards to poor outcomes, QOL physical function was significantly lower among frail participants than non-frail participants. This is in agreement with previously reported findings for community-dwelling older adults [30] and specific chronic condition patients with HIV [31], chronic kidney disease [32], and rheumatoid arthritis [33]. Additionally, frail participants had lower QOL social function than non-frail participants. These results were expected, since frailty has previously been associated with poor social function and living alone [34].

The psychological consequences of frailty on older adults should not be overlooked, as frailty can predispose elderly people to perceiving themselves as weak and fragile upon facing stress in their daily lives. Depression and frailty are considered as being two factors with a reciprocal interaction [35]. Our study findings support this association between frailty and depression, revealing that frail older adults are significantly more likely than non-frail older adults to suffer from depression. Similarly, the present study found frail older adults to be five times more likely than non-frail older adults of having impaired cognitive ability. This is in concordance with a systematic review by Brigola and colleagues [36], in which mild cognitive impairment, dementia, and mortality were all found to be associated with frailty.

Disability was considered as an adverse outcome among community-dwelling older adults, whereby frailty explained part of the variation in disability. It is important to consider the role of frailty in predicting disability among older adults in their later stages of life. Frailty and disability are similar experiences, and interventions tailored to combat disability should also address frailty as a prominent predictor of disability at earlier stages. In the current study, one finding which was different from the findings of previous reports was regarding the association between frailty and hospitalization. A recent metaanalysis of eight studies found being frail to be associated with a higher risk of hospitalization among older adults aged 65 years or over [37]. Further, a recent systematic review of ten studies also indicated that frail and pre-frail older adults were significantly more likely than non-frail older adults to be hospitalized [38]. However, the present study found no association between frailty and the risk of 
hospitalization, which may be explained by the small sample size or the fact that the participants were aged 60-65 years, as opposed to 65 years or above in other studies. It is also possible that decisions regarding the hospitalization of older adults are different in middle eastern cultures, such as the Jordanian one, than in other cultures around the world. Most previous studies have indicated an association between increased age and the onset of frailty. Frailty has been associated with many adverse outcomes that increase the need for additional health services, therefore increasing the burden on the families of frail older adults and on society in general. Therefore, the relationship between increased age and frailty is considered a major health challenge for healthcare providers [39].

\section{Conclusion}

Frailty was found to be highly prevalent among older adults in their later stages of life in Jordan, leading to several adverse outcomes such as depression, cognitive impairment, reduced quality of life, and disability. Frailty was predicted by gender and marital status, but not other demographic characteristics. The high levels of frailty, depression, and cognitive dysfunction and low quality of life among the participants is concerning, particularly considering the close-knit nature of Jordanian communities and the fact that some participants were as young as 60 years of age.

\section{Declarations}

\section{*Ethics approval and consent to participate}

The Institutional Review Boards of Jordan University of Science and Technology (IRB \#.. 34/77/2014) and Consenting participants signed a written consent form.

\section{*Consent for publication}

Not Applicable

\section{*Availability of data and material}

Not applicable. Data can be requested from the first author: Audai A. Hayajneh

\section{*Competing interests}

All authors have no financial and non-financial competing interests

\section{*Funding}

No funding was obtained for this study

\section{*Authors' contributions}

All authors have made substantial contributions to all of the following: 
$\mathrm{AH}$ and $\mathrm{HH}$ designed the study. DW assisted with IRB approvals. AH collected the data. $\mathrm{HH}$ analyzed the data. $\mathrm{AH}, \mathrm{HH}, \mathrm{EA}, \mathrm{DW}, \mathrm{MR}$ prepared the manuscript. All authors approved the final version for submission.

\section{*Acknowledgements}

Thanks for Jordan University of Science and Technology.

\section{References}

1. Masel, M. C., Graham, J. E., Reistetter, T. A., Markides, K. S., \& Ottenbacher, K. J. Frailty and health related quality of life in older Mexican Americans. Health Qual Life Outcomes. 2009;7:70. doi: 10.1186/1477-7525-7-70.

2. Vaughan, L., Corbin, A. L., \& Goveas, J. S. Depression and frailty in later life: a systematic review. Clin Interv Aging. 2015;10:1947. doi: 10.2147/CIA.S69632.

3. Bandeen-Roche, K., Xue, Q.-L., Ferrucci, L., et al. Phenotype of frailty: characterization in the women's health and aging studies. J Gerontol A Biol Sci Med Sci. 2006;61(3):262-266. https://doi.org/10.1093/gerona/61.3.262

4. Fried, L.P., Tangen, C. M., Walston, J., et al. Frailty in older adults: evidence for a phenotype. $J$ Gerontol A Biol Sci Med Sci. 2001;56(3):M146-M157. doi: 10.1093/gerona/56.3.m146.

5. Buchman, A. S., Yu, L., Wilson, R. S., et al. Brain pathology contributes to simultaneous change in physical frailty and cognition in old age. J Gerontol A Biol Sci Med Sci. 2014;69(12):1536-1544. doi: 10.1093/gerona/glu117.

6. Buigues, C., Padilla-Sánchez, C., Garrido, J. F., Navarro-Martínez, R., Ruiz-Ros, V., \& Cauli, O. The relationship between depression and frailty syndrome: a systematic review. Aging Ment Health. 2015;19(9):762-772. doi: 10.1080/13607863.2014.967174.

7. Panza, F. Loxupone, Ml., Solfrizzi, V., et al. Different cognitive frailty models and health- and congnitive-related outcomes in older age: from epidemiology to prevention. J Alzheimers Dis. 2018;62:993-1012. doi: 10.3233/JAD-170963

8. Cesari, M., Landi, F., Vellas, B., Bernabei, R., \& Marzetti, E. Sarcopenia and physical frailty: two sides of the same coin. Front. Aging Neurosci. 2014;6:192. doi: 10.3389/fnagi.2014.00192

9. Hare, D. L., Toukhsati, S. R., Johansson, P., \& Jaarsma, T. Depression and cardiovascular disease: a clinical review. Eur Heart J. 2013;35(21):1365-1372. doi: 10.1093/eurheartj/eht462.

10. Potter, G. G., McQuoid, D. R., Whitson, H. E., \& Steffens, D. C. Physical frailty in late life depression is associated with deficits in speed dependent executive functions. Int $J$ Geriatr Psychiatry. 2016;31(5):466-474. doi: 10.1002/gps.4351.

11. Quiñones, A. R., Markwardt, S., \& Botoseneanu, A. Multimorbidity combinations and disability in older adults. J Gerontol A Biol Sci Med Sci. 2016;71(6):823-830. doi: 10.1093/gerona/glw035.

12. Collard, R.M., Arts, M., Comijs, H.C., et al. The role of frailty in the association between depression and somatic comorbidity: Results from the baseline data of an ongoing prospective cohort study. Int 
J Nurs Stud. 2015;52:188-196. doi: 10.1016/j.jinurstu.2014.07.007

13. Hanssen, D. J., Naarding, P., Collard, R. M., Comijs, H. C., \& Voshaar, R. C. O. Physical, lifestyle, psychological, and social determinants of pain intensity, pain disability, and the number of pain locations in depressed older adults. PAIN. 2014;155(10):2088-2096. doi: 10.1016/j.pain.2014.07.019.

14. Penninx, B. W., Milaneschi, Y., Lamers, F., \& Vogelzangs, N. Understanding the somatic consequences of depression: biological mechanisms and the role of depression symptom profile. BMC Med. 2013;11(1):129. DOI: 10.1186/1741-7015-11-129.

15. Brown, P.J., Rutherford, B.R., Yaffe, K., et al. The depressed frail phenotype: the clinical manifestation of increased biological aging. Am J Geriatr Psychiatry. 2016;24(11):1084-1094. doi: 10.1016/j.jagp.2016.06.005.

16. Hayajneh, A.A.. The psychometric properties of the Arabic version of the Tilburg Frailty Indicator. Glob J Health Sci. 2019;11(9):123-133. doi:10.5539/gjhs.v11n9p123

17. Gobbens, R. J., van Assen, M. A., Luijkx, K. G., Wijnen-Sponselee, M. T., \& Schols, J. M. The Tilburg Frailty Indicator: Psychometric properties. J Am Med Dir Assoc. 2010;11(5):344-355. doi: 10.1016/j.jamda.2009.11.003.

18. Greenberg, S. A. 2012. The geriatric depression scale (GDS). Hartford Inst Geriatr Nurs. 2012;4(1):1-2.

19. Chaaya, M., Sibai, A., El Roueiheb, Z., Chemaitelly, H., Chahine, L. M., Al-Amin, H., \& Mahfoud, Z. (2008). Validation of the Arabic version of the short Geriatric Depression Scale (GDS-15). Int Psychoger. 2008;20(3):571-581. doi.org/10.1017/S1041610208006741

20. Nasreddine, Z. S., Phillips, N. A., Bédirian, V., Charbonneau, S., Whitehead, V., Collin, I., . . Chertkow, H. The Montreal Cognitive Assessment, MoCA: A brief screening tool for mild cognitive impairment. $J$ Am Geriatr Soc. 2005;53(4):695-699. doi: 10.1111/j.1532-5415.2005.53221.x

21. Rahman, T., \& El Gaafary, M. Montreal Cognitive Assessment Arabic version: reliability and validity prevalence of mild cognitive impairment among elderly attending geriatric clubs in Cairo. Geriatr Gerontol Int. 2009;9(1):54-61. doi:10.1111/j.1447-0594.2008.00509.

22. Ware Jr, J. E. SF-36 health survey update. Spine. 2000,25(24):3130-3139. doi:10.1097/00007632200012150-00008

23. Rand Corporation.(n.d.). SF 36 Health Survey, https://www.rand.org/healthcare/surveys_tools/mos/36-item-short-form.html

24. JMP®, Version 14.1. SAS Institute Inc., Cary, NC, 1989-2019

25. Biritwum, R., Minicuci, N., Yawson, A., Theou, O., Mensah, G., Naidoo, N., . . Jiang, Y. Prevalence of and factors associated with frailty and disability in older adults from China, Ghana, India, Mexico, Russia and South Africa. Maturitas. 2016;91:8-18. doi: 10.1016/j.maturitas.2016.05.012.

26. Zhang, Q., Guo, H., Gu, H., \& Zhao, X. Gender-associated factors for frailty and their impact on hospitalization and mortality among community-dwelling older adults: a cross-sectional populationbased study. Peer J. 2018;6: e4326. doi: 10.7717/peerj.4326. 
27. Gordon, E., Peel, N., Samanta, M., Theou, O., Howlett, S., \& jjHubbard, R. 2017. Sex differences in frailty: A systematic review and meta-analysis. Exp gerontol. 2017;89:30-40. doi: 10.1016/j.exger.2016.12.021.

28. Trevisan, C., Veronese, N., Maggi, et al. Marital status and frailty in older people: gender differences in the Progetto Veneto Anziani Longitudinal Study. J Womens Health. 2016;25(6):630-637. doi: $10.1089 /$ jwh.2015.5592

29. Yamanashi, H., Shimizu, Y., Nelson, M., et al. The association between living alone and frailty in a rural Japanese population: the Nagasaki Islands study. J Prim Health Care. 2015;7(4):269-273.

30. de Labra, C., Maseda., A., Lorenzo-Lopez, L., et al. Social factors and quality of life aspects on frailty syndrome in community dwelling older adults: The VERISAUDE study. BMC Geriatr. 2018;18:66. doi: 10.1186/s12877-018-0757-8.

31. Brañas, F., Jiménez, Z., Sánchez-Conde, et al. Frailty and physical function in older HIV-infected adults. Age Ageing. 2017;46(3):522-526. doi: 10.1093/ageing/afx013.

32. Walker, S. R., Gill, K., Macdonald, K., et al. Association of frailty and physical function in patients with non-dialysis CKD: a systematic review. BMC Nephrol. 2013;14(1):228. doi:10.1186/1471-2369-14228

33. Andrews, J., Covinsky, K., Hough, C., Trupin, L., Yelin, E. H., \& Katz, P. P. 2016. Frailty Is Associated with Decreased Physical Function in Adults with Rheumatoid Arthritis [abstract]. Arthritis Rheumatol. 2016; 68 (suppl 10). https://acrabstracts.org/abstract/frailty-is-associated-with-decreased-physicalfunction-in-adults-with-rheumatoid-arthritis/. Accessed July 31, 2019.

34. Hoogendijk, E. O., Suanet, B., Dent, E., Deeg, D. J., \& Aartsen, M. J. Adverse effects of frailty on social functioning in older adults: results from the Longitudinal Aging Study Amsterdam. Maturitas. 2016;83:45-50. doi:10.1016/j.maturitas.2015.09.002.

35. Soysal, P., Veronese, N., Thompson, T., et al. Relationship between depression and frailty in older adults: A systematic review and meta-analysis. Ageing Res Rev. 2017;36:78-87. doi: 10.1016/j.arr.2017.03.005

36. Brigola, A. G., Rossetti, E. S., Santos, B. R. et al. Relationship between cognition and frailty in elderly: a systematic review. Dement Neuropsychol. 2015;9(2):110-119. doi: 10.1590/198057642015 DN92000005.

37. Chang, S., Lin, H., \& Cheng, C. The relationship of frailty and hospitalization among older people: evidence from a meta-analysis. J Nurs Scholarsh. 2018;50(4):383-391. doi:10.1111/jnu.12397

38. Kojima, G. Frailty as a predictor of emergency department utilization among community-dwelling older people: a systematic review and meta-analysis. J Am Med Dir Assoc. 2019;20(1):103-105. doi:10.1016/j.jamda.2018.10.004

39. Buckinx, F., Rolland, Y., Reginster, J.-Y., Ricour, C., Petermans, J., \& Bruyère, O. Burden of frailty in the elderly population: perspectives for a public health challenge. Arch Public Health. 2015;73(1):19. doi: 10.1186/s13690-015-0068-x 


\section{Tables}

Table 1. Life Course Determinants of Community Dwelling Older Adults ( $N=109)$

\begin{tabular}{|c|c|c|}
\hline Variable & $\mathrm{n}(\%)$ & Mean (SD) \\
\hline Age & & $67.57(6.95)$ \\
\hline \multicolumn{3}{|l|}{ Gender } \\
\hline Male & $66(61 \%)$ & \\
\hline Female & $43(39 \%)$ & \\
\hline \multicolumn{3}{|l|}{ Marital Status } \\
\hline Married & $71(68 \%)$ & \\
\hline Divorced & $3(3 \%)$ & \\
\hline Widowed & $20(19 \%)$ & \\
\hline Single & $11(10 \%)$ & \\
\hline \multicolumn{3}{|l|}{ Marital Status (Total) } \\
\hline No & $34(32 \%)$ & \\
\hline Yes & $71(68 \%)$ & \\
\hline \multicolumn{3}{|l|}{ Education } \\
\hline Illiterate & $31(32 \%)$ & \\
\hline High School & $33(34 \%)$ & \\
\hline University Degree & $33(34 \%)$ & \\
\hline \multicolumn{3}{|l|}{ Income } \\
\hline$\otimes 450 \mathrm{JD}$ & $44(48 \%)$ & \\
\hline $450-650 \mathrm{JD}$ & $21(23 \%)$ & \\
\hline $650-950$ JD & $15(16 \%)$ & \\
\hline$\otimes 950 \mathrm{JD}$ & $10(11 \%)$ & \\
\hline Refused to Answer & $1(1 \%)$ & \\
\hline Living with Family Members (\#) & & $5.21(3.57)$ \\
\hline \multicolumn{3}{|l|}{ Living Alone } \\
\hline No & $90(83 \%)$ & \\
\hline Yes & 19 (17\%) & \\
\hline
\end{tabular}


Notes: SD: Standard Deviation

Table 2. Frailty and Its Outcomes in Community Dwelling Older Adults ( $N=109)$

\begin{tabular}{|c|c|c|}
\hline Variable & $\mathrm{n}(\%)$ & Mean (SD) \\
\hline Frailty & & $7.00(3.4)$ \\
\hline Non-Frail & $24(22 \%)$ & \\
\hline Frail & $85(78 \%)$ & \\
\hline Depression & & $6.12(3.56)$ \\
\hline Non-depressed & $68(62 \%)$ & \\
\hline Depressed & $41(38 \%)$ & \\
\hline \multicolumn{3}{|l|}{ Disability } \\
\hline Yes & $6(6 \%)$ & \\
\hline No & $103(94 \%)$ & \\
\hline Physical Domain & & $3.71(2.33)$ \\
\hline Psychological Domain & & $1.95(1.03)$ \\
\hline Social Domain & & $1.34(0.94)$ \\
\hline Comorbidity & 2.69 & (2.69) 1.94 \\
\hline Mild Cognitive impairment & & $25.02(3.25)$ \\
\hline Non-impaired & $62(57 \%)$ & \\
\hline Impaired & $47(43 \%)$ & \\
\hline Physical Function (PF-QOL) & & $55.05(27.21)$ \\
\hline Social Function (SF-QOL) & & $58.18(22.98)$ \\
\hline \multicolumn{3}{|c|}{ Hospitalized during the past Year } \\
\hline Yes & $33(30 \%)$ & \\
\hline No & 76 (70\%) & \\
\hline
\end{tabular}

Notes: SD: Standard Deviation; QOL: Quality of Life

Table 3. Differences in frailty among Education Groups (ANOVA) 


\begin{tabular}{|lllllll|}
\hline $\begin{array}{l}\text { Education } \\
\text { Level }\end{array}$ & $\begin{array}{l}\text { - Education } \\
\text { Level }\end{array}$ & Difference & $\begin{array}{l}\text { Standard Error } \\
\text { Differences }\end{array}$ & $\begin{array}{l}\text { Lower } \\
\text { Cl }\end{array}$ & Upper Cl & $\begin{array}{l}\text { *p- } \\
\text { Value }\end{array}$ \\
\hline Illiterate & University & 3.067449 & 0.8318036 & 1.08657 & 5.048324 & $0.0011^{*}$ \\
\hline Illiterate & High school & 2.037146 & 0.8318036 & 0.05627 & 4.018021 & $0.0424 *$ \\
\hline
\end{tabular}

Note. ${ }^{\star} p$ value $<0.05, \mathrm{Cl}$ : Confidence Interval 